\title{
The Effect of Concrete Mix Composition on the Character of Fractures of Set Concrete
}

\author{
Janusz Konkol ${ }^{1} \&$ Grzegorz Prokopski $^{1}$ \\ ${ }^{1}$ Department of Materials Engineering and Technology of Building, Rzeszow University of Technology, \\ Rzeszów, Poland \\ Correspondence: Janusz Konkol, Department of Materials Engineering and Technology of Building, Rzeszów \\ University of Technology, Powstańców Warszawy 6, 35-959 Rzeszów, Poland. Tel: 48-17-865-1701. E-mail: \\ janusz.konkol@prz.edu.pl
}

Received: December 28, 2013 Accepted: September 16, 2014 Online Published: October 24, 2014

doi:10.5539/jgg.v6n4p29

URL: http://dx.doi.org/10.5539/jgg.v6n4p29

\begin{abstract}
The article presents the results of strength, stereological and fractographical tests and examinations carried out on concretes made based on two coarse aggregates: basalt and gravel types. A relationship was demonstrated to exist between the strength characteristics of concretes and the fractal dimension, as determined by the chord method. The concrete of poorer strength properties had higher fractal dimension values of its fractures, whereas the concrete of the best strength parameters was characterized by the lowest fractal dimension value.

A relationship was found between the stereological parameters (the mortar fraction, $V_{V m o r}$, the coarse aggregate relative area, $S_{V C}$, and the air pore relative area, $S_{V P}$ ) and the fracture surface morphology described by the fractal dimension, as determined by the chord method, $D_{C}$.
\end{abstract}

Keywords: fractal geometry, stereology, fractography, fracture mechanics, concrete

\section{Introduction}

One of the possibilities of the quantitative investigation of concrete structure is the analysis of the surface morphology of fractures formed during cracking. The measure of concrete fracture surface complexity is the fractal dimension, $D$ (Mandelbrot, 1977). Studies carried out in recent years have proven the suitability of fractal geometry for the description of fracture surfaces of numerous materials, including also concretes and mortars (Winsolw, 1985). Works on this subject, which have been published so far, show a relationship to exist between the fractal dimension, $D$, and the properties of concretes: the compressive strength, $f_{c}$ (e.g., Prokopski \& Konkol, 2005; Yan et al., 2002), the fracture toughness, as expressed by the critical stress intensity factor, $K_{I c}$ (e.g., Prokopski \& Konkol, 2005; Saouma \& Barton, 1994; Brandt \& Prokopski, 1993), the fracture energy, $G_{F}$ (Saouma \& Barton, 1994; Brandt \& Prokopski, 1993; Issa et al., 1993; Yan et al., 2001), or Young's modulus, $E$ (e.g., Prokopski \& Konkol, 2005).

A decisive influence on the strength characteristics (fracture mechanics parameters) of concretes is exerted by coarse aggregate. Investigations carried out have shown that fracture toughness of concrete depends on the surface morphology and grain shape of coarse aggregate grains (Bochenek \& Prokopski, 1989; Prokopski et al., 1997). In the case of a concrete based on cobble aggregate with a smooth surface and an oval shape, crack propagation occurs at lower stresses than for broken aggregate with an irregular shape and a rough surface. This is due to the better adhesion (by higher cohesion forces) of cement paste to the broken aggregate grains that are rough and of an irregular shape.

The effect of the type of aggregate, the maximal grain size and the water/binder ratio is analyzed in work (Yan et al., 2003). The conclusion emerging from the tests carried out is formulated as follows: the increase in the aggregate grain size and in the water/binder ratio causes an increase in the fractal dimension, while the aggregate type has an effect on the fractal dimension value. The following coarse aggregates were used in these tests: cobble, broken, and lightweight aggregates. The highest fractal dimension value was obtained for broken aggregate concrete $(D=2.121)$, the intermediate value for cobble aggregate concrete $(D=2.083)$ and the lowest value for lightweight aggregate concrete $(D=2,072)$.

In their tests on gravel aggregate and basalt aggregate concretes, Saouma and Barton (1994) have found that with 
increasing fracture surface fractal dimension, the values of the parameters $G_{F}$ and $K_{I c}$ decrease. Based on the obtained results, they have formulated the following relationships:

$$
\begin{aligned}
G_{F} & =1380.7-1043.9 \cdot D \mathrm{~N} / \mathrm{m} \\
\mathrm{K}_{\text {Ic }} & =6.837-5.239 \cdot D \mathrm{MNm}^{-3 / 2}
\end{aligned}
$$

In work (Yan et al., 2002), a linear increase in fracture energy with increasing fractal dimension is obtained for concretes of identical composition, but made with two different water/binder ratios:

$$
\begin{aligned}
& G_{F}=-12.48+1802 \cdot(D-2), \text { for water/bindr ratio }=0.44 \\
& G_{F}=-21.00+2730 \cdot(D-2), \text { for water/binder ratio }=0.26
\end{aligned}
$$

In both cases, the coefficient of linear correlation was $R=0.986$.

The increase in fracture energy with increasing fractal dimension is also confirmed by the studies of Issa et al. (1993).

The results of analysis concerning the fracture toughness of concretes made from three different aggregates (dolomite, gravel and basalt aggregate) and the relationship between fracture mechanics parameters and compressive strength, and the fractal dimension, as determined by the chord method, are provided in work (Prokopski \& Konkol, 2005). The tests were carried out after 7, 14, 28 and 90 days of concrete curing, respectively. For 28 days' concrete, the following correlation equations are obtained:

$$
\begin{aligned}
& K_{I c}^{S}=61.69-57.59 \cdot D \quad \mathrm{MN} / \mathrm{m}^{3 / 2} \\
& f_{C}=1947.6-1842.2 \cdot D \mathrm{MPa} \\
& E=970.44-912.08 \cdot D \quad \mathrm{GPa}
\end{aligned}
$$

The fractal examination was also used for the analysis of cracks on concrete surfaces. In their tests on concrete reinforced with steel fibres, Yan et al. (2002) obtained a good correlation between the compressive strength and the fractal dimension of those fractures, as determined by the covering method. They found a larger number of cracks on the concrete specimen surfaces in the case of specimens with the highest content of steel fibres, which resulted in an increase in the fractal dimension. They put forward a formula relating the compressive strength with the fractal dimension, which has the following form:

$$
f_{c}=79.9+81.4 \cdot(D-1)
$$

The correlation coefficient of this relationship is $R=0.995$.

Another example of seeking for a relationship between the compressive strength and the fractal dimension is the study of Ficker (2008). In his investigation of cement gel, he presented an equipotential dependence of compressive strength on the fractal dimension, which was obtained with a correlation coefficient of 0.978 . The investigation was carried out for water-cement ratio values varying from 0.4 to 1.4 . The author demonstrated also that the fractal dimension increased equipotentially $(R=0.979)$ as the water-cement ratio decreased.

Another relationship between the fracture mechanics parameters and the fractal dimension was the subject of study (Zhang \& Wei, 2010a). The issue of seeking for a concrete fracture model that will reflect the actual behaviour of the fracture phenomenon still remains topical (Zhang \& Wei, 2009; Zhang \& Wei, 2010b). Modelling applies also to fatigue fractures (Carpinteri et. al., 2008).

\section{Method}

\subsection{Testing Programme}

The relationship between fracture surface morphology and fracture mechanics on one part, and the compressive strength of concretes on the other is determined in this work.

The testing programme was set up based on the two-factor design with two repetitions of the test at the central point (Figure 1). The design was considered optimal in terms of two selection criteria, namely: feasibility, information capability and efficiency.

The tests were carried out for five intermediate input quantities $x_{1}$ and $x_{2}$, determined for the normalized values of $\hat{x}_{i}$ equal to: $0, \pm 1, \pm 1.414$, respectively. The number of repetitions in fracture toughness testing according to 
Mode I of fracture was four, while in compressive strength testing - six. The specimens were made from concretes based on natural, cobble (gravel) and broken (basalt) aggregate, respectively, of a fraction of up to 16 $\mathrm{mm}$. The CEM I 32.5 R Portland cement was used for the tests. The variables in the composition of concretes were the water-cement $(W / C)$ ratio in the range from 0.41 to 0.61 and the amount of coarse aggregate in relation to sand $\left(C_{\text {agg. }} / F_{\text {agg }}\right)$. For broken aggregate, this value ranged from 1.6 to 3.0, and for natural aggregate - from 1.5 to 3.5. Within the same concrete, a constant cement-to-sand ratio was assumed. In broken aggregate concretes, this was 1:1.76, while in natural aggregate concretes $-1: 1.38$.

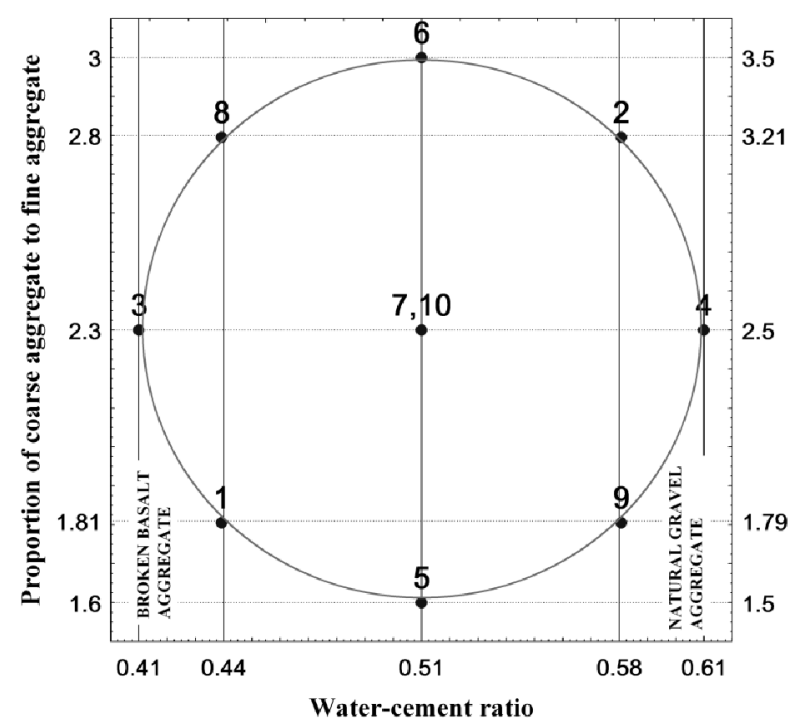

Figure 1. Test design

Ten series of concretes were made, which differed in concrete mix composition (Table 1).

Table 1 . Summary of the quantities of components in $1 \mathrm{~m}^{3}$ of concrete mixes $(B C$ - basalt concrete, $G C-$ gravel concrete)

\begin{tabular}{|c|c|c|c|c|c|c|c|c|c|c|c|}
\hline \multirow{3}{*}{$\begin{array}{l}\text { Series } \\
\text { no. }\end{array}$} & \multicolumn{3}{|c|}{ Real variables } & \multicolumn{8}{|c|}{ Proportions of components per $1 \mathrm{~m}^{3}$ of concrete $\mathrm{mix}, \mathrm{kg} / \mathrm{m}^{3}$} \\
\hline & \multirow{2}{*}{$\begin{array}{c}W / C \\
\left(x_{1}\right)\end{array}$} & \multicolumn{2}{|c|}{$C_{\text {agg. }} / F_{\text {agg }}\left(x_{2}\right)$} & \multicolumn{2}{|c|}{$\begin{array}{c}\text { Cement } \\
C \\
\end{array}$} & \multicolumn{2}{|c|}{$\begin{array}{c}\text { Water } \\
W \\
\end{array}$} & \multicolumn{2}{|c|}{$\begin{array}{l}\text { Sand } \\
F_{a g g} \\
\end{array}$} & \multicolumn{2}{|c|}{$\begin{array}{c}\text { Coarse aggregate } \\
C_{a g g .} \\
\end{array}$} \\
\hline & & $B C$ & $G C$ & $B C$ & $G C$ & $B C$ & $G C$ & $B C$ & $G C$ & $B C$ & $G C$ \\
\hline 1 & 0.44 & 1.81 & 1.79 & 396 & 451 & 174 & 198 & 698 & 623 & 1261 & 1116 \\
\hline 2 & 0.58 & 2.80 & 3.21 & 306 & 323 & 178 & 188 & 540 & 446 & 1508 & 1430 \\
\hline 3 & 0.41 & 2.30 & 2.50 & 358 & 391 & 147 & 160 & 631 & 540 & 1450 & 1350 \\
\hline 4 & 0.61 & 2.30 & 2.50 & 334 & 363 & 204 & 221 & 588 & 501 & 1353 & 1252 \\
\hline 5 & 0.51 & 1.60 & 1.50 & 405 & 469 & 206 & 239 & 714 & 646 & 1142 & 970 \\
\hline 6 & 0.51 & 3.00 & 3.50 & 301 & 315 & 154 & 161 & 531 & 434 & 1592 & 1521 \\
\hline 7 & 0.51 & 2.30 & 2.50 & 345 & 377 & 176 & 192 & 609 & 520 & 1400 & 1299 \\
\hline 8 & 0.44 & 2.80 & 3.21 & 320 & 339 & 141 & 149 & 564 & 467 & 1576 & 1499 \\
\hline 9 & 0.58 & 1.81 & 1.79 & 375 & 424 & 218 & 246 & 661 & 585 & 1194 & 1049 \\
\hline 10 & 0.51 & 2.30 & 2.50 & 345 & 377 & 176 & 192 & 609 & 520 & 1400 & 1299 \\
\hline
\end{tabular}

\subsection{Testing of the Mechanical Properties of Concretes}

For each test design arrangement, four $8 \times 15 \times 70 \mathrm{~cm}$ specimens were made for the determination of fracture toughness according to Mode I of fracture (Figure 2), and six $10 \mathrm{~cm}$-edge cubes for compressive strength tests. The specimens were conditioned under air-humid conditions (with a relative humidity of $>95 \%$ ). The strength tests were performed after 28 days of concrete curing. 


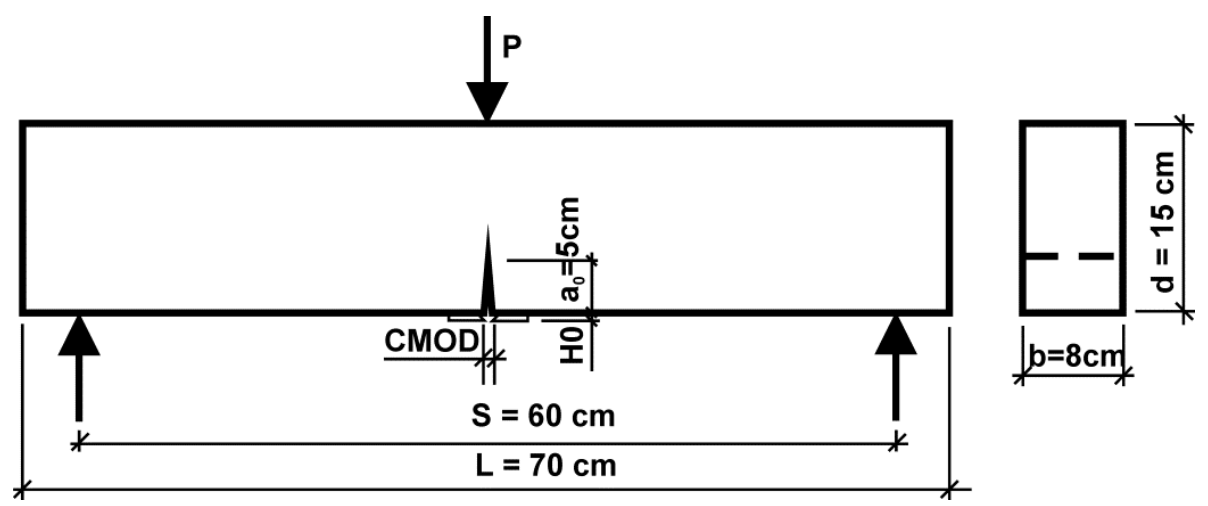

Figure 2. Method of loading a notched beam in the fracture toughness test

The following were determined in the fracture toughness tests, according to RILEM TC 89 - FMT (1990):

- critical stress intensity factor, $K_{I c}^{S}$,

- unit failure work, $J_{I c}$,

- modulus of elasticity at bending, $E$.

The obtained strength testing results, along with the standard deviation of the mean value, are given in Table 2.

Table 2. The mean values of parameters determined

\begin{tabular}{ccccccccc}
\hline \multirow{2}{*}{$\begin{array}{c}\text { Series } \\
\text { no. }\end{array}$} & \multicolumn{7}{c}{$K_{I c}^{S} \pm S, \mathrm{MN} / \mathrm{m}^{3 / 2}$} & \multicolumn{7}{c}{$J_{I c} \pm S, \mathrm{~N} / \mathrm{m}$} & \multicolumn{2}{c}{$E \pm S, \mathrm{GPa}$} & \multicolumn{2}{c}{$f_{c} \pm S, \mathrm{MPa}$} \\
\cline { 2 - 9 } & $B C$ & $G C$ & $B C$ & $G C$ & $B C$ & $G C$ & $B C$ & $G C$ \\
\hline 1 & $1.54 \pm 0.04$ & $1.20 \pm 0.03$ & $31.8 \pm 1.5$ & $25.6 \pm 2.1$ & $34.4 \pm 1.2$ & $19.3 \pm 1.2$ & $56.4 \pm 1.1$ & $54.3 \pm 0.7$ \\
2 & $1.36 \pm 0.02$ & $0.93 \pm 0.05$ & $25.0 \pm 0.4$ & $20.4 \pm 2.2$ & $32.0 \pm 1.7$ & $17.2 \pm 1.0$ & $52.2 \pm 1.1$ & $39.9 \pm 1.5$ \\
3 & $1.51 \pm 0.12$ & $1.14 \pm 0.07$ & $40.9 \pm 1.1$ & $19.7 \pm 1.4$ & $35.3 \pm 1.3$ & $22.6 \pm 0.8$ & $72.6 \pm 1.0$ & $52.4 \pm 1.5$ \\
4 & $1.28 \pm 0.04$ & $0.92 \pm 0.04$ & $25.3 \pm 0.9$ & $17.7 \pm 2.0$ & $30.4 \pm 1.3$ & $18.3 \pm 1.0$ & $44.4 \pm 0.4$ & $35.2 \pm 0.3$ \\
5 & $1.53 \pm 0.06$ & $0.90 \pm 0.02$ & $26.8 \pm 1.9$ & $15.2 \pm 1.7$ & $31.3 \pm 1.6$ & $17.3 \pm 1.0$ & $44.3 \pm 1.3$ & $40.4 \pm 0.6$ \\
6 & $1.65 \pm 0.06$ & $1.12 \pm 0.06$ & $35.3 \pm 3.2$ & $18.0 \pm 1.6$ & $34.8 \pm 0.6$ & $19.9 \pm 1.5$ & $55.2 \pm 2.0$ & $46.7 \pm 1.0$ \\
7 & $1.48 \pm 0.05$ & $1.08 \pm 0.08$ & $29.5 \pm 4.1$ & $18.1 \pm 1.2$ & $35.0 \pm 0.8$ & $19.6 \pm 1.5$ & $54.4 \pm 1.1$ & $46.8 \pm 0.8$ \\
8 & $1.55 \pm 0.08$ & $1.20 \pm 0.01$ & $36.9 \pm 1.4$ & $23.6 \pm 2.1$ & $34.5 \pm 1.2$ & $20.8 \pm 1.4$ & $63.5 \pm 1.1$ & $49.7 \pm 1.0$ \\
9 & $1.21 \pm 0.04$ & $0.89 \pm 0.02$ & $24.6 \pm 1.6$ & $13.4 \pm 1.1$ & $27.8 \pm 0.9$ & $17.3 \pm 1.1$ & $43.8 \pm 0.8$ & $32.1 \pm 0.9$ \\
10 & $1.53 \pm 0.07$ & $1.10 \pm 0.05$ & $38.3 \pm 2.4$ & $18.4 \pm 1.4$ & $34.3 \pm 1.8$ & $19.6 \pm 0.9$ & $50.3 \pm 1.0$ & $45.9 \pm 1.4$ \\
\hline
\end{tabular}

$S-$ standard error.

The increase in water-cement ratio and the lower fraction of coarse aggregate of the concrete mix in both concrete types resulted in a decline of mechanical characteristics tested, i.e. the critical stress intensity factor, $K_{I c}^{S}$; the unit failure work, $J_{I c}$; Young's modulus, E; and the compressive strength, $f_{c}$. Higher values of the parameters tested were obtained for basalt concretes, compared to gravel aggregate concretes.

\subsection{Stereological Tests}

Stereological tests were carried out on the ground surfaces of $8 \times 15 \mathrm{~cm}$ specimens. The specimens were cut out from bars used for fracture toughness testing. The method of surface preparation of concrete test specimens is described in work (Konkol \& Prokopski, 2004).

The concrete specimen surfaces, after having been scanned at a resolution of 400 dpi., were subjected to stereological analysis that was performed using the FRAKTAL_Stereolog software application (Konkol). From 40 to 56 areas, each of a surface area of $20.54 \mathrm{~cm}^{2}$ (which totalled from 821.6 to $1150.2 \mathrm{~cm}^{2}$ ) were subjected to examination. The minimum diameters of pores analyzed were $0.2 \mathrm{~mm}$. The method of interpretation of the locations of air pore occurrence, on the image of a sample basalt concrete microsection, is shown in Figure 3. 

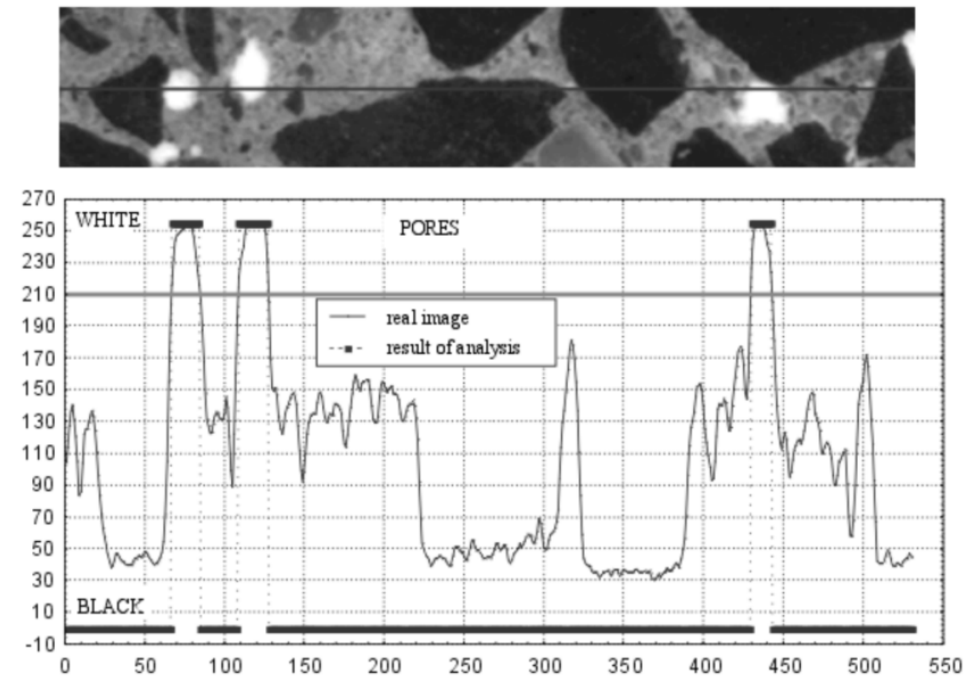

Figure 3. Graphical interpretation of the locations of air pore occurrence - basalt concrete

In the stereological tests, the relative air pore area, $S_{V P}$, and the relative coarse aggregate grain area, $S_{V C}$, were determined. The obtained results are summarized in Table 3.

Table 3. Results of the stereological analysis of air pores and coarse aggregate grains

\begin{tabular}{|c|c|c|c|c|c|c|c|}
\hline \multirow{3}{*}{$\begin{array}{c}\text { Series } \\
\text { no. }\end{array}$} & \multicolumn{4}{|c|}{ Basalt concrete } & \multicolumn{3}{|c|}{ Gravel concrete } \\
\hline & \multicolumn{2}{|c|}{ Variable } & \multicolumn{2}{|c|}{ Stereological parameters } & \multirow{2}{*}{$\frac{\text { Variable }}{C_{\text {agg. }} / F_{\text {agg }}}$} & \multicolumn{2}{|c|}{ Stereological parameters } \\
\hline & $W / C$ & $C_{a g g .} / F_{a g g}$ & $\begin{array}{l}S_{V P} \pm S \\
\mathrm{~cm}^{2} / \mathrm{cm}^{3}\end{array}$ & $\begin{array}{l}S_{V C} \pm S, \\
\mathrm{~cm}^{2} / \mathrm{cm}^{3}\end{array}$ & & $\begin{array}{l}S_{V P} \pm S \\
\mathrm{~cm}^{2} / \mathrm{cm}^{3}\end{array}$ & $\begin{array}{l}S_{V C} \pm S \\
\mathrm{~cm}^{2} / \mathrm{cm}^{3}\end{array}$ \\
\hline 1 & 0.44 & 1.81 & $1.35 \pm 0.007$ & $6.31 \pm 0.007$ & 1.79 & $2.30 \pm 0.013$ & $8.10 \pm 0.14$ \\
\hline 2 & 0.58 & 2.80 & $0.99 \pm 0.008$ & $7.03 \pm 0.012$ & 3.21 & $2.03 \pm 0.030$ & $8.77 \pm 0.13$ \\
\hline 3 & 0.41 & 2.30 & $1.27 \pm 0.008$ & $6.79 \pm 0.009$ & 2.50 & $2.68 \pm 0.022$ & $10.54 \pm 0.18$ \\
\hline 4 & 0.61 & 2.30 & $0.89 \pm 0.006$ & $6.67 \pm 0.008$ & 2.50 & $1.96 \pm 0.010$ & $8.58 \pm 0.15$ \\
\hline 5 & 0.51 & 1.60 & $1.50 \pm 0.011$ & $5.48 \pm 0.010$ & 1.50 & $2.51 \pm 0.020$ & $5.87 \pm 0.12$ \\
\hline 6 & 0.51 & 3.00 & $0.88 \pm 0.008$ & $8.00 \pm 0.015$ & 3.50 & $2.81 \pm 0.017$ & $11.05 \pm 0.25$ \\
\hline 7 & 0.51 & 2.30 & $0.87 \pm 0.006$ & $6.55 \pm 0.009$ & 2.50 & $2.47 \pm 0.029$ & $8.38 \pm 0.19$ \\
\hline 8 & 0.44 & 2.80 & $0.74 \pm 0.005$ & $7.07 \pm 0.009$ & 3.21 & $2.77 \pm 0.034$ & $10.80 \pm 0.08$ \\
\hline 9 & 0.58 & 1.81 & $0.96 \pm 0.010$ & $5.98 \pm 0.011$ & 1.79 & $1.84 \pm 0.016$ & $6.29 \pm 0.25$ \\
\hline 10 & 0.51 & 2.30 & $0.97 \pm 0.006$ & $6.35 \pm 0.008$ & 2.50 & $2.47 \pm 0.024$ & $8.50 \pm 0.23$ \\
\hline
\end{tabular}

\subsection{Fracture Surface Examinations}

The fractal and fractographical examinations of fracture surfaces were performed on specially prepared gypsum replicas made on the fractures of concrete bars previously used in fracture toughness tests. 24 fracture surfaces were randomly chosen for examination. Stained gypsum was poured on the concrete fracture replicas made of white gypsum. So prepared specimens were slit along the longer side into $5 \mathrm{~mm}$-thick 10 strips, to obtain 20 profile lines for each fracture (Figure 4). This adoption of the slitting direction was intended to obtain profile lines that would be approximately consistent with the direction of crack propagation. The slit specimens were scanned at a resolution of 600 dpi., and the profile line coordinates were obtained using the FRAKTAL_Digit software application (Konkol) (Figure 5) (Konkol \& Prokopski, 2007). The computation of the fractal dimension $D$ was carried out by the chord and the box methods using the FRAKTAL_Wymiar2D (Konkol). The obtained computation results are summarized in Table 4, where the extreme (minimum and maximum) values of fractal dimension are shown in bold. 


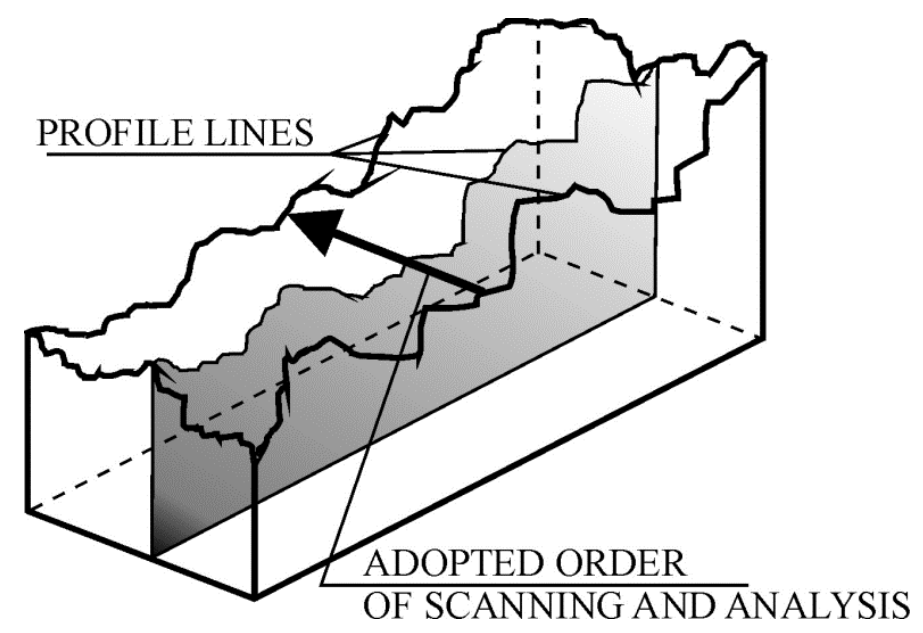

Figure 4. Direction of scanning of fracture surfaces
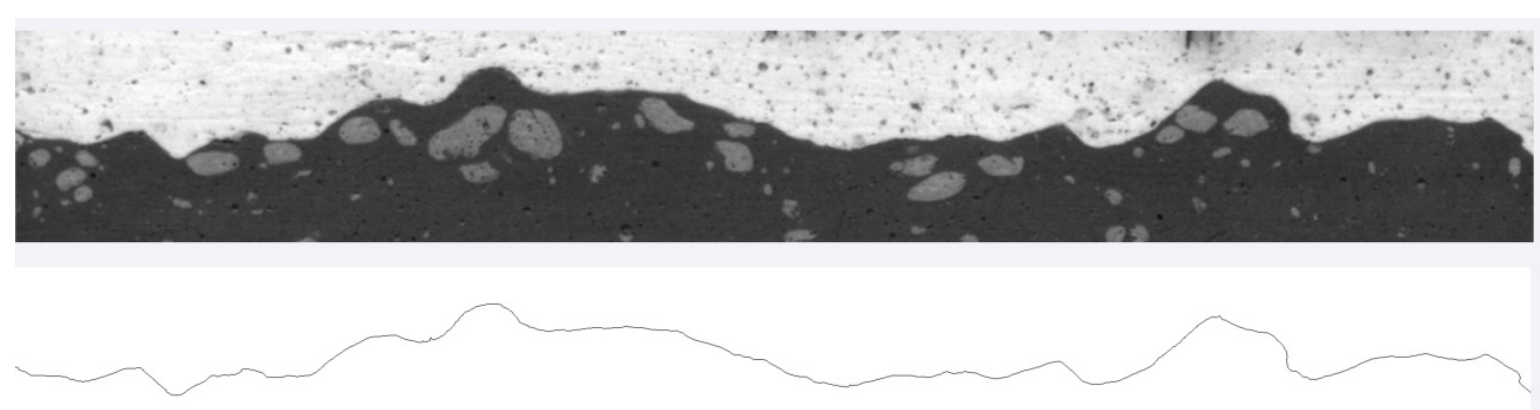

Figure 5. Fracture profile scanned at a resolution of 600 dpi. and the result of digitalization

Based on the measurements made, the mean values of the profile line development factor, $R_{L}$. and of the fracture surface development factor, $R_{S}$, were computed by the cycloid method, as discussed e.g. in the work by Wojnar (1990) (Table 5).

Table 4. Results of the examination of profile line fractal dimension for basalt and gravel concretes

\begin{tabular}{cccccccc}
\hline \multirow{2}{*}{$\begin{array}{c}\text { Series } \\
\text { no. }\end{array}$} & \multicolumn{3}{c}{ Basalt concrete } & \multicolumn{2}{c}{ Gravel concrete } \\
\cline { 2 - 8 } & \multicolumn{2}{c}{ Variable } & \multicolumn{2}{c}{ Fractal dimension } & Variable & \multicolumn{2}{c}{ Fractal dimension } \\
\hline 1 & 0.44 & 1.81 & $1.0241 \pm 0.0008$ & $1.0643 \pm 0.0018$ & 1.79 & $\mathbf{1 . 0 2 3 6} \pm 0.0010$ & $1.0618 \pm 0.0014$ \\
2 & 0.58 & 2.80 & $1.0240 \pm 0.0007$ & $1.0641 \pm 0.0013$ & 3.21 & $1.0253 \pm 0.0010$ & $\mathbf{1 . 0 6 7 2} \pm 0.0012$ \\
3 & 0.41 & 2.30 & $\mathbf{1 . 0 2 1 6} \pm 0.0008$ & $\mathbf{1 . 0 6 0 2} \pm 0.0010$ & 2.50 & $1.0248 \pm 0.0011$ & $\mathbf{1 . 0 5 9 5} \pm 0.0012$ \\
4 & 0.61 & 2.30 & $1.0235 \pm 0.0009$ & $1.0619 \pm 0.0013$ & 2.50 & $1.0274 \pm 0.0011$ & $1.0645 \pm 0.0015$ \\
5 & 0.51 & 1.60 & $1.0238 \pm 0.0010$ & $1.0630 \pm 0.0017$ & 1.50 & $1.0281 \pm 0.0013$ & $1.0641 \pm 0.0016$ \\
6 & 0.51 & 3.00 & $1.0240 \pm 0.0010$ & $1.0681 \pm 0.0018$ & 3.50 & $\mathbf{1 . 0 2 9 2} \pm 0.0010$ & $1.0668 \pm 0.0019$ \\
7 & 0.51 & 2.30 & $1.0227 \pm 0.0008$ & $1.0639 \pm 0.0017$ & 2.50 & $1.0275 \pm 0.0011$ & $1.0663 \pm 0.0016$ \\
8 & 0.44 & 2.80 & $1.0227 \pm 0.0006$ & $1.0646 \pm 0.0013$ & 3.21 & $1.0286 \pm 0.0012$ & $1.0670 \pm 0.0014$ \\
9 & 0.58 & 1.81 & $\mathbf{1 . 0 2 5 3} \pm 0.0010$ & $\mathbf{1 . 0 7 1 5} \pm 0.0015$ & 1.79 & $1.0267 \pm 0.0011$ & $\mathbf{1 . 0 6 7 2} \pm 0.0018$ \\
10 & 0.51 & 2.30 & $1.0227 \pm 0.0007$ & $1.0624 \pm 0.0013$ & 2.50 & $1.0272 \pm 0.0010$ & $1.0612 \pm 0.0016$ \\
\hline
\end{tabular}

Based on the measurements made, the mean values of the profile line development factor, $R_{L}$. and of the fracture surface development factor, $R_{S}$, were computed by the cycloid method, as discussed e.g. in the work by Wojnar (1990) (Table 5). 
Table 5. Summary of the results of profile line fractographical examination

\begin{tabular}{ccccccccc}
\hline \multirow{2}{*}{$\begin{array}{c}\text { Series } \\
\text { no. }\end{array}$} & \multicolumn{4}{c}{ Basalt concrete } & \multicolumn{5}{c}{ Gravel concrete } \\
\cline { 2 - 9 } & $C_{\text {agg. }} / F_{\text {agg }}$ & $R_{L^{ \pm} S}$ & $R_{S^{ \pm} S}$ & $W / C$ & $C_{\text {agg. }} / F_{\text {agg }}$ & $R_{L^{ \pm} S}$ & $R_{S^{ \pm} S}$ \\
\hline 1 & 0.44 & 1.81 & $1.246 \pm 0.009$ & $1.442 \pm 0.016$ & 0.44 & 1.79 & $1.241 \pm 0.008$ & $1.422 \pm 0.012$ \\
2 & 0.58 & 2.80 & $1.248 \pm 0.007$ & $1.441 \pm 0.012$ & 0.58 & 3.21 & $1.262 \pm 0.007$ & $1.461 \pm 0.012$ \\
3 & 0.41 & 2.30 & $\mathbf{1 . 2 2 9} \pm 0.006$ & $\mathbf{1 . 4 0 6} \pm 0.010$ & 0.41 & 2.50 & $\mathbf{1 . 2 2 7} \pm 0.007$ & $\mathbf{1 . 4 0 1} \pm 0.011$ \\
4 & 0.61 & 2.30 & $1.244 \pm 0.007$ & $1.426 \pm 0.011$ & 0.61 & 2.50 & $1.257 \pm 0.009$ & $1.453 \pm 0.013$ \\
5 & 0.51 & 1.60 & $1.251 \pm 0.010$ & $1.437 \pm 0.016$ & 0.51 & 1.50 & $1.258 \pm 0.010$ & $1.449 \pm 0.015$ \\
6 & 0.51 & 3.00 & $1.267 \pm 0.012$ & $1.474 \pm 0.019$ & 0.51 & 3.50 & $1.273 \pm 0.012$ & $1.476 \pm 0.019$ \\
7 & 0.51 & 2.30 & $1.250 \pm 0.009$ & $1.439 \pm 0.015$ & 0.51 & 2.50 & $1.268 \pm 0.009$ & $1.466 \pm 0.014$ \\
8 & 0.44 & 2.80 & $1.248 \pm 0.007$ & $1.439 \pm 0.011$ & 0.44 & 3.21 & $\mathbf{1 . 2 7 5} \pm 0.008$ & $\mathbf{1 . 4 7 9} \pm 0.013$ \\
9 & 0.58 & 1.81 & $\mathbf{1 . 2 9 0} \pm 0.010$ & $\mathbf{1 . 5 0 5} \pm 0.015$ & 0.58 & 1.79 & $1.270 \pm 0.010$ & $1.465 \pm 0.016$ \\
10 & 0.51 & 2.30 & $1.240 \pm 0.007$ & $1.425 \pm 0.011$ & 0.51 & 2.50 & $1.241 \pm 0.008$ & $1.423 \pm 0.013$ \\
\hline
\end{tabular}

The least fractal dimension values, as determined by both methods, were obtained for Series 3 basalt concrete of the lowest water-cement ratio $(W / C=0.41)$ and of the best mechanical properties (the highest values of $E, J_{I c}$ and $f_{c}$ ). Also in the fractographical examination of the fractures of this concrete, the lowest values of the profile line development factor, $R_{L}$, and of the fracture surface development factor, $R_{S}$, were obtained.

In the case of the basalt concrete, which exhibited by the poorest mechanical characteristics: $K_{I c}^{S}, J_{I c}, E$ and $f_{c}$ (Series 9), the highest fractal dimension value, as determined by both the chord $\left(D_{C}=1.0253\right)$ and the box $\left(D_{B C}\right.$ $=1.0715$ ) methods, was obtained. It was found, at the same time, that also the parameters $R_{L}$ and $R_{S}$ are the higher, the poorer strength characteristics are possessed by concrete.

Obtaining the least values of all fractographical parameters determined was the result of the decreasing cohesion forces at the coarse aggregate/cement paste interface and the consequence of the occurrence of a high-roughness along-grain fracture. Hence, the conclusion can be drawn, that the fracture surface of a concrete characterized by higher strength (with the aggregate/cement paste contact layer of higher strength) are more flat as a result of fracture occurring across the coarse aggregate grains (the inter-grain fracture, Figure 6).

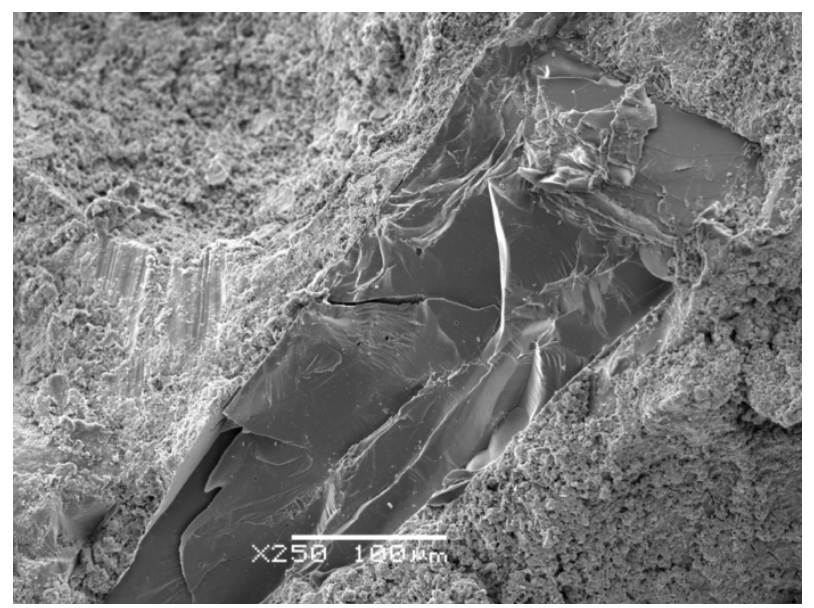

Figure 6. Microstructure of broken aggregate concrete $\left(W / C=0.51\right.$ and $C_{a g g} / F_{\text {agg }}=3.0$, Series 6$)$. A cross-fractured basalt grain is visible

It was found from the fractographical examination that the fracture surfaces of basalt aggregate concretes were characterized by higher values of the factors $R_{L}$ and $R_{S}$ compared to those of gravel aggregate concretes. The effect of the shape and roughness of coarse aggregate grains becomes visible here. Gravel grains with a smooth surface and an oval shape contribute to a lesser fracture surface complexity resulting in lower values of the factors $R_{L}$ and $R_{S}$. Due to their sharp shape and high roughness, basalt grains, on the other hand, result in higher values of the factors $R_{L}$ and $R_{S}$. The dependence of the fractal dimension on the variables in the test design is 
represented by Figures 7 and 8 .
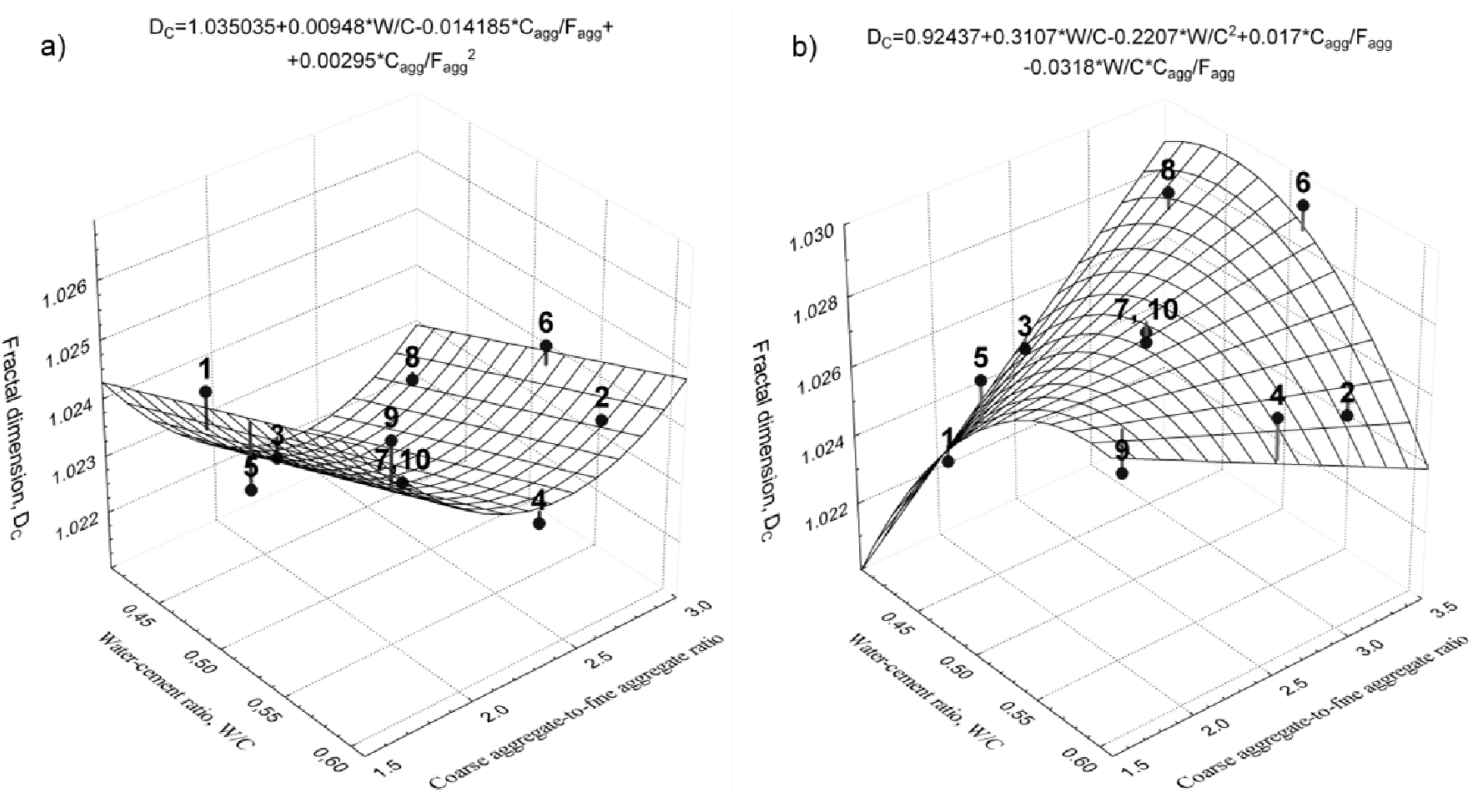

Figure 7. Relationship of the fractal dimension, $D_{C}$, as determined by the chord method, versus the water/cement ratio, $W / C$, and the coarse aggregate-to-fine aggregate ratio, $C_{\text {agg. }} / F_{\text {agg }}$

a) basalt concrete, b) gravel concrete

a) $\quad \mathrm{D}_{\mathrm{BC}}=1.03470+0.14168^{*} \mathrm{~W} / \mathrm{C}-0.01062^{*} \mathrm{C}_{\text {agg }} / \mathrm{F}_{\text {agg }}{ }^{+}$
$+0.008348^{*} \mathrm{C}_{\text {agg }} / \mathrm{F}_{\text {agg }}{ }^{2}-0.054488^{*} \mathrm{~W} / \mathrm{C}^{*} \mathrm{C}_{\text {agg }} / \mathrm{F}_{\text {agg }}$

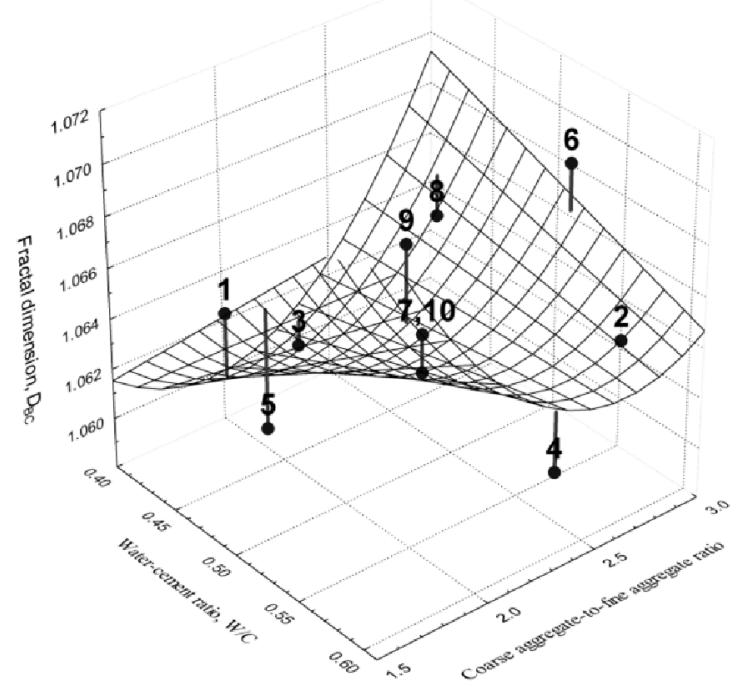

b) $\quad \mathrm{D}_{\mathrm{BC}}=1.03371+0.08803^{*} \mathrm{~W} / \mathrm{C}-0.000448^{*} \mathrm{C}_{\mathrm{agg}} / \mathrm{F}_{\mathrm{agg}}{ }^{+}$ $+0.003082^{*} \mathrm{C}_{\text {agg }} / \mathrm{F}_{\text {agg }}{ }^{2}-0.026212^{*} \mathrm{~W} / \mathrm{C}^{*} \mathrm{C}_{\text {agg }} / \mathrm{F}_{\text {agg }}$

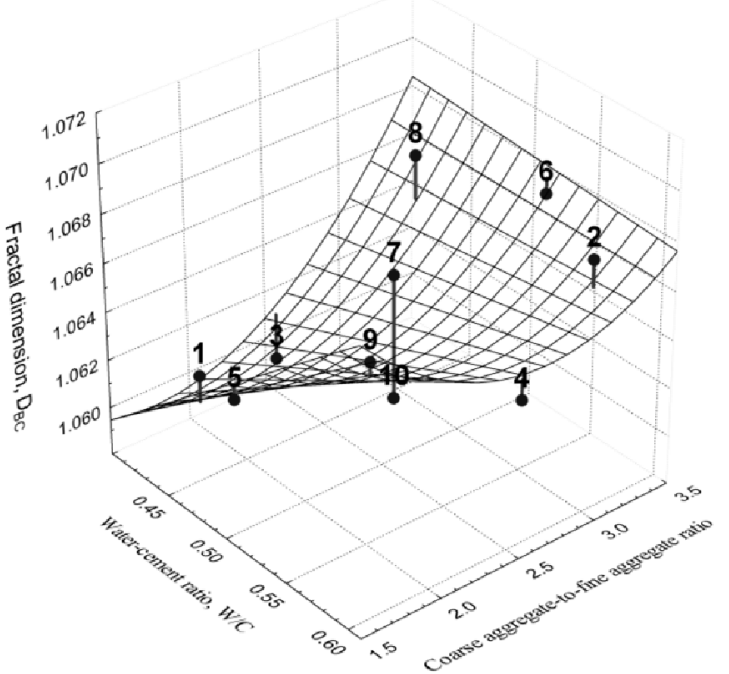

Figure 8. Relationship of the fractal dimension, $D_{B C}$, as determined by the box method, versus the water/cement ratio, $W / C$, and the coarse aggregate-to-fine aggregate ratio, $C_{\text {agg. }} / F_{\text {agg }}$

a) basalt concrete, b) gravel concrete

Table 10 gives the values of correlation coefficients for adopted regression models.

From the analyses carried out it was found that the most appropriate method for determining the fractal dimension of the concrete fracture profile line was the chord method. In the examination carried out by this method, an increase in fractal dimension with decreasing $W / C$ ratio was noted. 
Table 10 . Values of the correlation coefficients, $R$, of approximating polynomials

\begin{tabular}{cccc}
\hline Concrete type & Fractal dimension & $\begin{array}{c}R \\
\text { (for all test design values) }\end{array}$ & $\begin{array}{c}R \\
\text { (for mean values) }\end{array}$ \\
\hline \multirow{2}{*}{ basalt } & $D_{C}$ & 0.558 & 0.865 \\
& $D_{B C}$ & 0.521 & 0.718 \\
\multirow{2}{*}{ gravel } & $D_{C}$ & 0.659 & 0.875 \\
& $D_{B C}$ & 0.473 & 0.832 \\
\hline
\end{tabular}

In contrast to the chord method (Figure 9b), the box method (Figure 9a) showed no sensitivity to the change of aggregate type. However, the effect of coarse aggregate quantity on the fractal dimension value became visible in both methods (Figures 9a and 9b). With increasing coarse aggregate fraction of concrete, a drop in the fractal dimension value occurred initially, followed subsequently by its increase. The observed minimum of $C_{\text {agg. }} / F_{\text {agg }}$ reached to approx. 2.3, which means that with this ratio of coarse aggregate to fine aggregate, an optimal chip pile was obtained. Only in the case of natural aggregate concrete and the use of the chord method was a linear relationship between coarse aggregate quantity and fractal dimension obtained (Figure 9b).
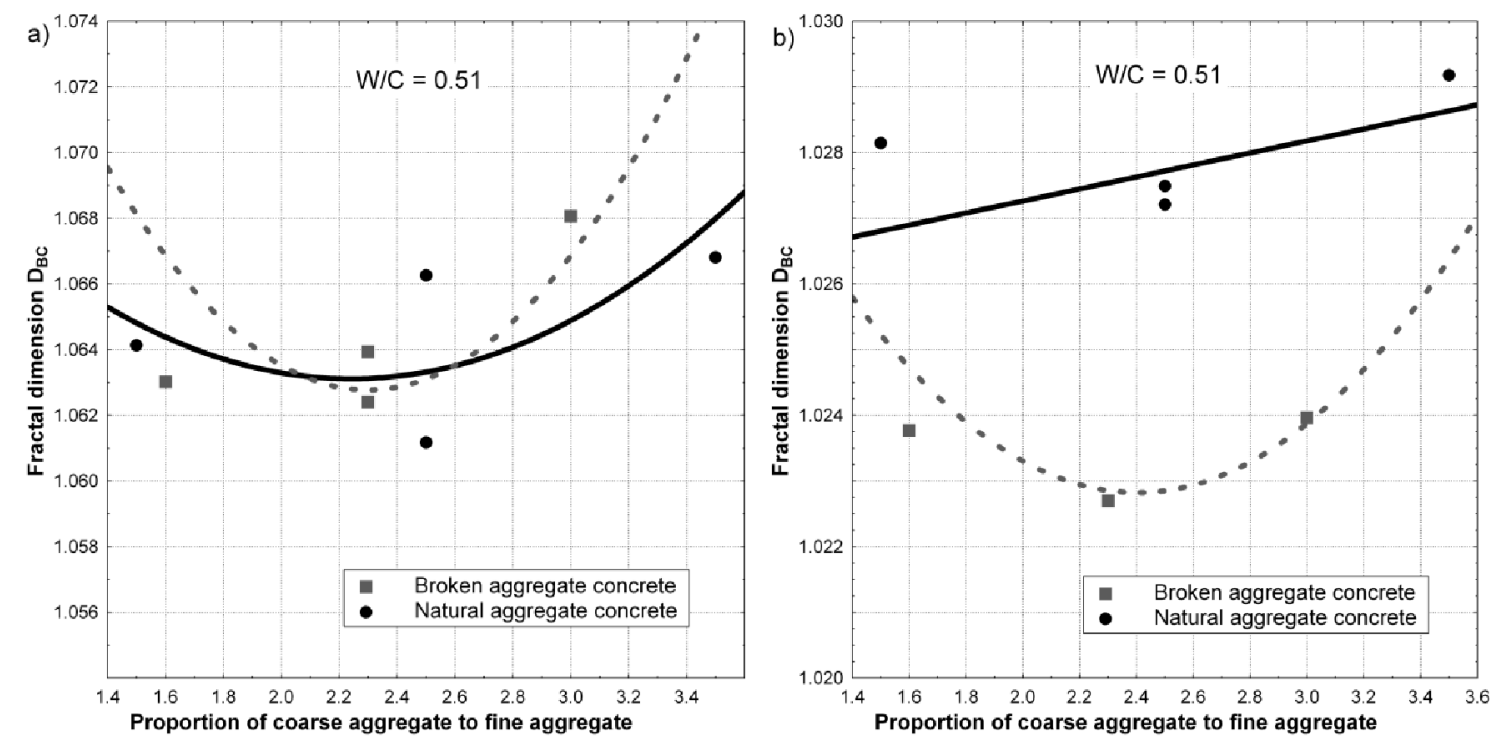

Figure 9. Comparison of relationships between fractal dimension and coarse aggregate fraction at the constant $W / C$ ratio $=0.51$ : a) the box method, b) the chord method

\subsection{Relationship between Fractal Dimension and the Properties of Concretes}

The performed analysis showed significant correlations between fractal dimension and the mechanical properties of concretes in the case of basalt concrete only (Figure 10) (for all results from 10 concrete series examined).

A significant correlation (at the significance level $p=0.05$ ) was found to exist between the fractal dimension, $D_{C}$, as determined by the chord method, and Young's modulus, $E$, the unit failure work, $J_{I c}$, and the compressive strength, $f_{c}$. With the increase in fractal dimension, all the above-mentioned concrete characteristics declined.

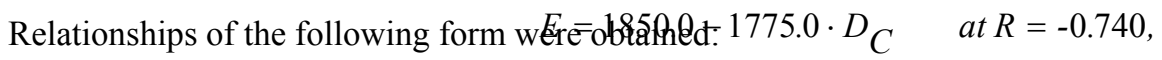

$$
J_{I c}=4426.4-4294.0 \cdot D_{C} \quad \text { at } R=-0.733 \text {, }
$$

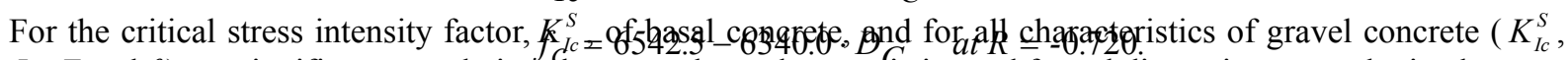
$J_{I c}, E$ and $f_{c}$ ), no significant correlations between these characteristics and fractal dimension were obtained.

The effect of the fractal dimension, $D$, on the mortar fraction, $V_{V m o r}$; the relative coarse aggregate grain area, $S_{V C}$; and the relative air pore area, $S_{V P}$, was also analyzed. It follows from this analysis that the effect of the relative 
air pore area, $S_{V P}$, on the value of the fractal dimension, $D$, is insignificant, whereas the effect of the parameters $V_{V m o r}$ and $S_{V C}$ is significant, with a significance level of 0.05 .

For the fractal dimension, $D$, the relationships derived have the following form:

- basalt concrete

$$
D_{C}=0.99200+0.00034 \cdot V_{V m o r}+0.00211 \cdot S_{V C}, \text { with } R=0.702 \text { and } p=0.09
$$

- gravel concrete

$$
D_{C}=1.05327-0.00028 \cdot V_{V m o r}-0.00144 \cdot S_{V C}, \text { with } R=0.714 \text { and } p=0.08
$$
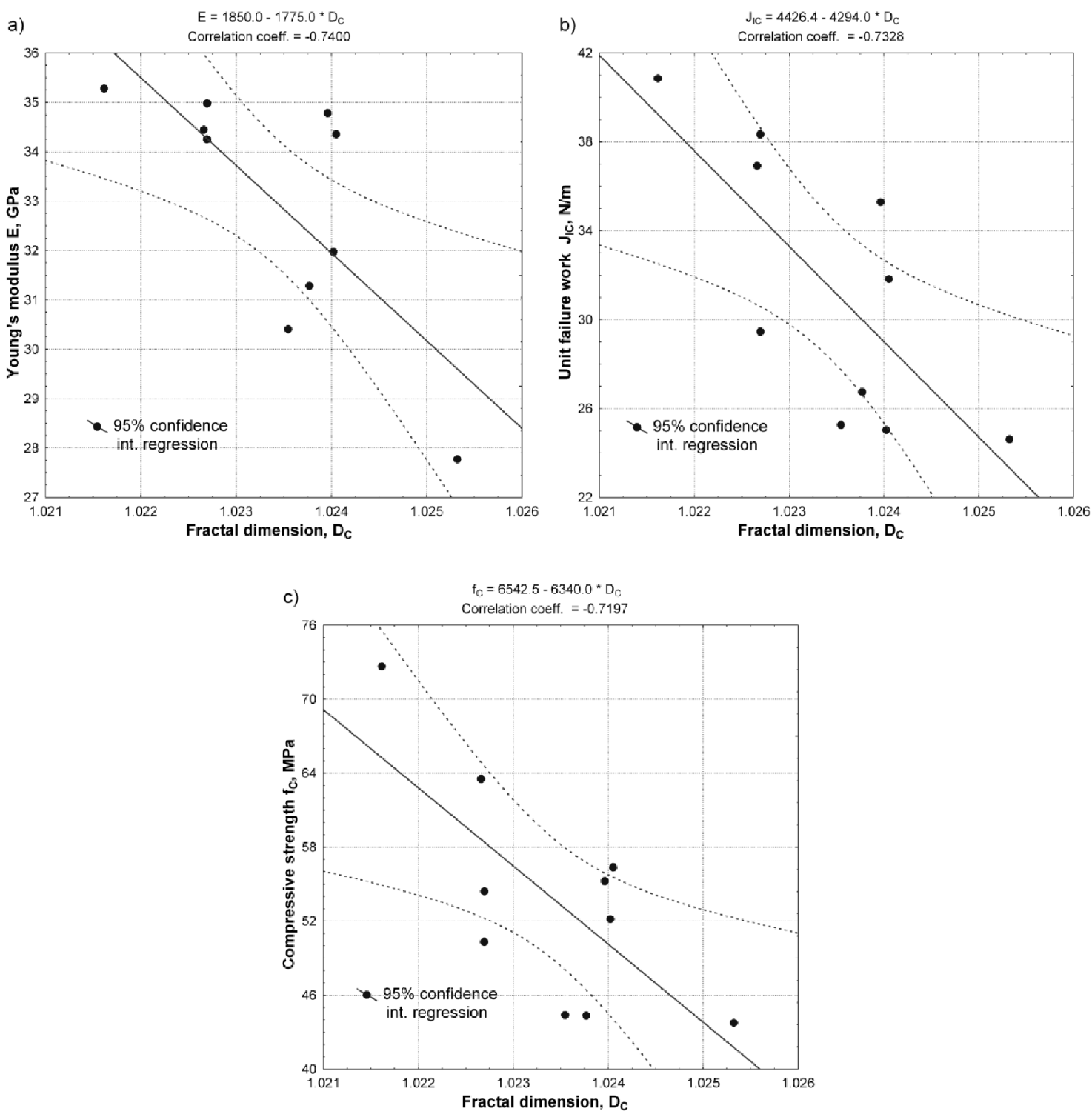

Figure 10. Basalt concrete - Fractal dimension dependence of: a) the $E$ module, b) the unit failure work, $J_{I c}$, and c) the compressive strength, $f_{c}$; with the fractal dimension, $D_{C}$, being determined by the chord method

The obtained significance levels indicate that the derived regression functions can be regarded as significant, assuming the significance level $p=0.1$. 
The different signs of the coefficients at the relative coarse aggregate grain area, $S_{V C}$ (Equations 6 and 7), indicate that the fractal dimension, $D_{C}$, varies depending on the coarse aggregate type (the effect of grain roughness and shape). The larger relative area of gravel, due to the smoothness and the oval shape of its grains, caused a decrease in fractal dimension (lesser fracture surface complexity), whereas the larger relative area of basalt contributed to an increase in the fractal dimension of basalt concrete fractures.

Additionally, in the case of gravel concrete, the relative coarse aggregate area, $S_{V C}$, was substituted with the aggregate volume, $V_{V C}$, (Figure 11). This improved the correlation coefficient and the significance level boundary value, at which the obtained correlation can be considered significant.
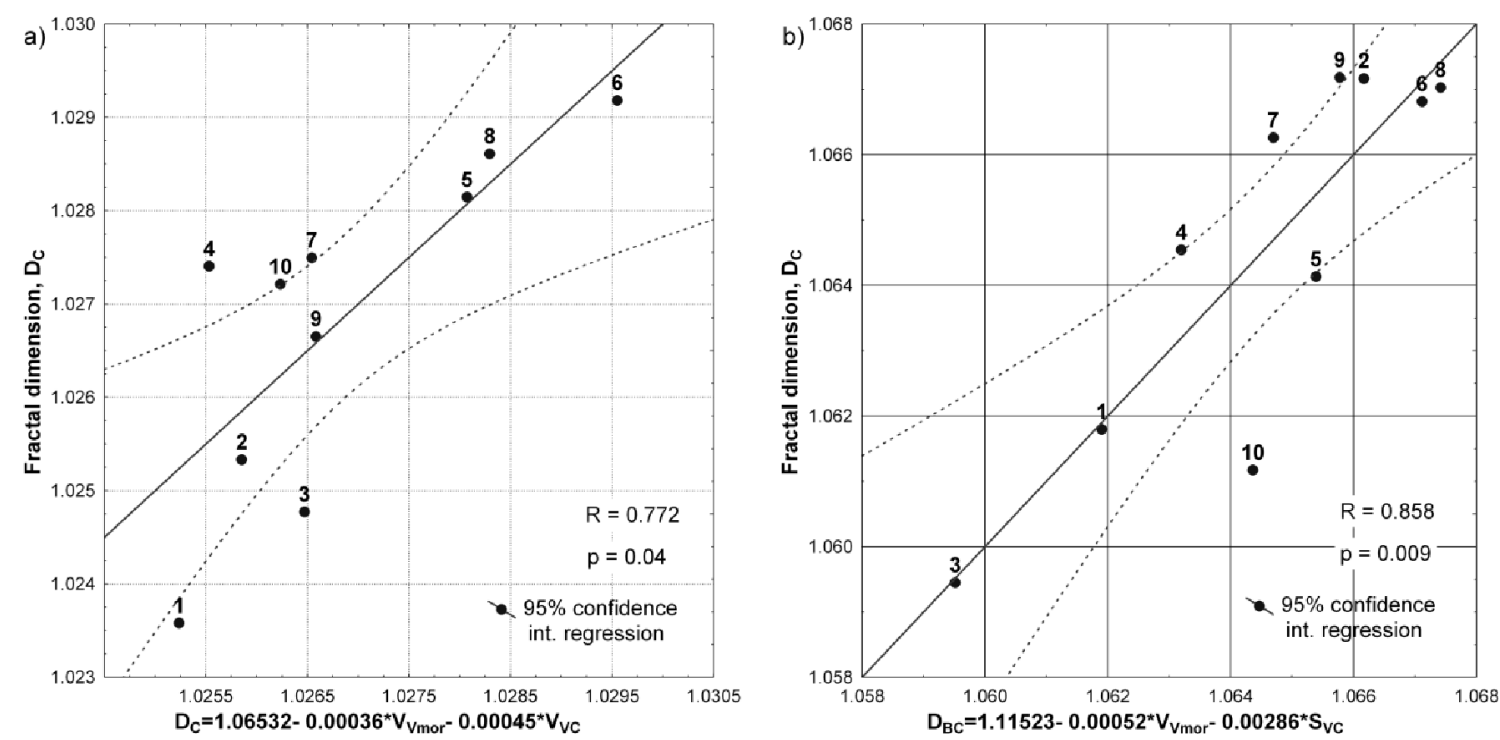

Figure 11. Relationships, obtained in gravel concretes, between the fractal dimension $D_{C}$ (determined by the chord method) and: a) the mortar fraction $V_{V m o r}$ and the relative coarse aggregate volume $V_{V C}$ b) the mortar fraction $V_{V m o r}$ and the relative coarse aggregate area $S_{V C}$

The multiple regression function has the form of:

$$
D_{C}=1.06532-0.00036 \cdot V_{V m o r}-0.00045 \cdot V_{V C}
$$

and is adequate at the significance level $p=0.05$.

The above relationship indicates that increasing the gravel aggregate fraction of concrete causes a decrease in the fracture fractal dimension, $D_{C}$.

In the case of the fractal dimension $D_{B C}$ (determined by the box method), correlations between the fractal dimension, and the mortar fraction $V_{V m o r}$ and the relative coarse aggregate area $S_{V C}$ were only obtained in gravel concretes (Figure 11b).

The obtained relationship has the form of:

$$
D_{B C}=1.11523-0.00052 \cdot V_{V m o r}-0.00286 \cdot S_{V C}
$$

\section{Discussion}

From the tests and analyses carried out, the following have been found:

- Fractal analysis confirms that the profile lines of concrete fractures are fractals and therefore can be subject to any operations that are specific to fractal geometry.

- The chord method is more appropriate for the determination of the fractal dimension of concrete fracture profile lines, as it is sensitive to the change of aggregate type. Greater fractal dimension values are obtained for 
concrete based on natural (gravel) aggregate compared to broken (basalt) aggregate concrete and concretes with a higher value of $W / C$.

- There is a relationship between the fractal dimension, $D$, and the factors $R_{L}$ and $R_{S}$; the increase in fractal dimension is accompanied by an increase in the parameters $R_{L}$ and $R_{S}$.

- Examination reveal the existence of a relationship between the fractal dimension of the fracture surface of the concretes examined and their mechanical properties. Significant correlations between the fractal dimension $D_{C}$, as determined by the chord method, and Young's modulus $E$, the unit failure work $J_{I c}$ and the compressive strength $f_{c}$ are only obtained for broken aggregate concrete. No significant correlations are, however, found in this case between the fractal dimension and the critical stress intensity factor $K_{I c}^{S}$.

- For natural gravel aggregate concrete, a significant correlation is found to exist between the fractal dimension $D_{C}$, and the mortar fraction of concrete mix $V_{V m o r}$ and the relative coarse aggregate volume $V_{V C}$. With increasing gravel aggregate volume in concrete, the value of the fractal dimension $D_{C}$ decreases, which results from the fact that the gravel grains with a smooth surface and an oval shape contribute to a lesser complexity of the surface of the forming fracture.

- Fractographical examination verify the relationship between the fracture character and the mechanical properties of concretes. The higher level of fracture surface complexity (higher values of $R_{L}$ and $R_{S}$ ), the poorer properties of concretes. This is caused by lower cohesion forces at the aggregate/cement paste interface and the occurrence of an along-grain fracture. In higher-strength concretes, the fracture occurs across the aggregate grains (the inter-grain fracture), and therefore the fracture surfaces are less rough (more flat).

- The suitability of the stereological methods for the determination of the air porosity of concrete on set concrete specimens using image analysis is confirmed, as well as is the suitability of the stereological parameters determined by these methods, for the evaluation of the characteristics of air pores and coarse aggregates.

\section{References}

Bochenek, A., \& Prokopski, G. (1989). The investigation of aggregate grain size effect on fracture toughness of ordinary concrete structures. International Journal of Fracture, 41(3), 197-205. http://dx.doi.org/10.1007/BF00018657

Brandt, A. M., \& Prokopski, G. (1993). On the fractal dimension of fracture surfaces of concrete elements. Journal of Materials Science, 28, 4762-4766. http://dx.doi.org/10.1007/BF00414269

Carpinteri, A., Spagnoli, A., Vantadori, S., \& Viappiani, D. (2008). Influence of the crack morphology on fatigue crack growth rate: A continuously-kinked crack model based on fractals. Engineering Fracture Mechanics, 75, 579-589. http://dx.doi.org/10.1016/j.engfracmech.2007.05.007

Determination of fracture parameters $\left(K_{I c}^{S}\right.$ and $\left.C T O D_{c}\right)$ of plain concrete using three-point bend test. RILEM Draft Recommendations, TC 89 - FMT Fracture Mechanics of Concrete Test Methods, Materials and Structures, 23, 1990.

Ficker, T. (2008). Fractal strength of cement gels and universal dimension of fracture surfaces. Theoretical and Applied Fracture Mechanics, 50, 167-171. http://dx.doi.org/10.1016/j.tafmec.2008.07.004

Issa, M. A., \& Hammad, A. M., \& Chudnovsky, A. (1993). Correlation between crack tortuosity and fracture toughness in cementitious material. International Journal of Fracture, 60, 97-105. http://dx.doi.org/10.1007/BF00012438

Konkol, J., \& Prokopski, G. (2004). Analysis of the fracture surface morphology of concrete by the method of vertical section. Computers and Concrete, 1(4), 389-400. http://dx.doi.org/10.5566/ias.v30.p89-100

Konkol, J., \& Prokopski, G. (2007). The necessary number of profile lines for the analysis of concrete fracture surfaces. Structural Engineering and Mechanics, 25(5), 565-576.

Mandelbrot, B. B. (1977). Fractals. Form, chance and dimension. San Francisco: Freeman.

Prokopski, G., Halbiniak, J., \& Langier, B. (1997). The examination of the fracture toughness of concretes with diverse structure. Journal of Materials Science, 33, 1819-1825. http://dx.doi.org/10.1023/A:1004345003089

Prokopski, G., \& Konkol, J. (2005). The fractal analysis of the fracture surface of concretes made from different coarse aggregates. Computers and Concrete, 2(3), 239-248. http://dx.doi.org/10.12989/cac.2005.2.3.239

Saouma, V. E., \& Barton, C. C. (1994). Fractals, fractures, and size effects in concrete. Journal of Engineering Mechanics, 120(4), 835-854. http://dx.doi.org/10.1061/(ASCE)0733-9399(1994)120:4(835) 
Winsolw, D. N. (1985) The fractal nature of the surface of cement paste. Cement and Concrete Research, 15, 817-824. http://dx.doi.org/10.1016/0008-8846(85)90148-6

Wojnar, L. (1990). Quantitative fractography. Basic principles and computer aided research. Scientific Booklets of the Cracow. Univ. of Techn., Mechanical Series, Booklet no. 2, Cracow (in Polish).

Yan, A., Wu, K., \& Zhang, X. (2002). A quqntitative study on the surface crack pattern of concrete with high content of steel fiber. Cement and Concrete Research, 32, 1371-1375. http://dx.doi.org/10.1016/S0008-8846(02)00788-3

Yan, A., Wu, K. R., Zhang, D., \& Yao, W. (2001). Effect of fracture path on the fracture energy of high-strength concrete. Cement and Concrete Research, 31, 1601-1606. http://dx.doi.org/10.1016/S0008-8846(01)00610-X

Yan, A., Wu, K. R., Zhang, D., \& Yao, W. (2003). Influence of concrete composition on the characterization of fracture surface. Cement and Concrete Composites, 25, 153-157. http://dx.doi.org/10.1016/S0958-9465(02)00004-5

Zhang, H, \& Wei, D. M. (2009). Fractal effect and anisotropic constitutive model for concrete. Theoretical and Applied Fracture Mechanics, 51, 167-173. http://dx.doi.org/10.1016/j.tafmec.2009.05.005

Zhang, H., \& Wei, D. M. (2010a). Fracture and damage behaviors of concrete in the fractal space. Journal of Modern Physics, 1, 48-58. http://dx.doi.org/10.4236/jmp.2010.11006

Zhang, H, \& Wei, DM. (2010b). Estimation of fracture toughness, driving force, and fracture energy for fractal cracks using the method of imaginary smooth crack. Engineering Fracture Mechanics, 77, 621-630. http://dx.doi.org/10.1016/j.engfracmech.2009.12.005

\section{Copyrights}

Copyright for this article is retained by the author(s), with first publication rights granted to the journal.

This is an open-access article distributed under the terms and conditions of the Creative Commons Attribution license (http://creativecommons.org/licenses/by/3.0/). 